\title{
III
}

\section{Introduction to Rabbi Israel Meir Kagan and the Mishna Berura}

\begin{abstract}
ittle is known about the early life and influences of the Hafetz Hayyim, Rabbi Yisrael Meir Kagan, and how he came to be commonly viewed as both a leader of the Jewish community in Eastern Europe and the most significant halakhic authority of the first half of the twentieth century. ${ }^{1}$ These accolades are above and beyond his otherwise well-known reputation as a pious and righteous man about whom legendary stories are told-he seems to have lived the life of a truly ethical and upright human being. From the vast and varied literature that he penned, however, one can catch a glimpse of who he was and how he perceived the world around him, and his perception would lead him to become one of the greatest sages of late nineteenth- and early twentieth-century Ashkenazic Jewry.
\end{abstract}

1 Rabbi Kagan was born in Zhetl, Belarus, on February 6, 1838 and died in Radun, Poland, on September 15, 1933. We are not writing a biography of Rabbi Israel Meir Kagan, although such is sorely needed. Nor are we writing a survey of his general intellectual approach. Rather, this work is an analysis of the methodology of the book Mishna Berura. It is neither a social nor an intellectual biography of Rabbi Kagan. Nor is this a study of specific questions in Jewish law. Rather, it is an examination of the methodological approach used to produce the Mishna Berura. The goal is to understand how the book addresses and analyzes questions of Jewish law and the practical approach that is taken to deal with legal ambiguity. 
Of the many tomes he wrote, the Mishna Berura ${ }^{2}$ is, without a doubt, Rabbi Kagan's greatest contribution to the canon of Orthodox Jewish law and the most complex; it is a singular work that synthesizes Jewish traditions, laws, and mores into a practical halakhic guide to daily religious life. What is also clear is that for all of his traditionalism, Rabbi Kagan was an iconoclast, and the Mishna Berura broke from many of the traditional approaches for deciding halakhic directives, such as the Shulhan Arukh's “Majority Rule” and the Gra's "Rule of Correctness," and even from other normative Orthodox approaches like Rabbenu Tam's ${ }^{3}$ dependence on local Jewish custom (Minhag Yisrael). Instead, he favored studying, engaging, and asserting decisions in a nuanced, almost natural approach to how ethical people should live their daily lives in a manner consistent with Jewish law. The specific answers as to how moral people should interact with their world while governed by Jewish law were often to be understood not in simple definitions of "right and wrong," but rather, in terms of the question: "How could one please his Creator and be his most authentic self, in any given situation?" As the terms and turns of life shift like the vagaries of a kaleidoscope, Rabbi Kagan's responses to these realities are equally nimble, subtle, and variegated, yet remain at once clear and defined. His perspective is not about observations of strictness versus leniency as much as it is about evaluating a spectrum of options; the same question could get a different answer depending on the situation. Through his singularly humane prism and holistic analysis of individual cases, he guides the common Jew toward an observant and meaningful life.

It is that very unique approach to comprehending and disseminating Jewish law that makes the Mishna Berura such a groundbreaking work. It seems to be an editorial, since it is written as a commentary, but it also shares a similarity to those works in the first

2 Mishnah Berura was written as a six-volume work, published intermittently from 1884 to 1907. See Mordecai Schreiber, Alvin Schiff, and Leon Klenicki, eds., The Shengold Jewish Encyclopedia, $3^{\text {rd }}$ ed. (Rockville: Shengold Books, 2003), 117.

3 Rabbi Jacob ben Meir (1100-c. 1171), grandson of Rashi, was a renowned French Tosafist and the foremost halakhic authority of his generation. 
category mentioned above, since it cites sources encyclopedically. At times, it even analyzes information in a manner similar to that of the Yam Shel Shlomo, probing the depths of halakhic development. Yet, despite its resemblance to these other forms, its overall halakhic methodology is wholly unique compared to that of both its predecessors and its successors. On the pages of what is known as a whole as the Mishna Berura, Rabbi Kagan includes, in addition to his main commentary (which is called Mishna Berura), two other commentaries, entitled Biur Halakha (on the outer edge of the page) and Sha'ar HaTziyun (on the bottom of the page). Though other legal scholars have written multiple works on a single topic, this layout of having different commentaries by one author on a single page is unique, not only because they reference each other but also because they are meant to be read concurrently. In our analysis, we will at times cite the Biur Halakha and the Sha'ar HaTziyun, but we will not be analyzing the methodologies of the two works on their own. Rather, references from these works will be used to support our analysis of the Mishna Berura. ${ }^{4}$

As major world events and subsequent transitions in Jewish history ${ }^{5}$ swirled around the enclave of Eastern European Jewry, the

4 The reason why we treat the two works as support to the Mishna Berura is that, in truth, the Biur Halakha and the Sha'ar HaTziyun are not wholly independent from the main commentary. Rather, the Biur Halakha explains and elaborates on the rulings found in the Mishna Berura, and gives detailed analyses of the sources used in the Mishna Berura to justify the rulings found therein. As such, the Biur Halakha is more similar to a collection of long, academic footnotes than it is another commentary or even a super-commentary. The Sha'ar HaTziyun is an even simpler work, since it typically just provides the bibliographic information that is lacking in the Mishna Berura, and only occasionally provides a qualification or limitation to the Mishna Berura's rulings. There are, however, a few cases where the Sha'ar HaTziyun contradicts the Mishna Berura, such as with respect to whether a Kohen who is acting as Hazan can also recite the Birkat Kohanim (Sha'ar HaTziyun 128:64), yet such cases are exceedingly rare. Nevertheless, they await scholarly explanation. The Mishna Berura also contains a number of "Star Footnotes," which qualify the main text. We hope to explain these "Star Footnotes" in a future publication.

5 The transitions in Eastern Europe from 1860 to 1910 were profound and paradigm-shifting, including the rise of the Reform Movement, the Mussar Movement, and Conservative Judaism, among others. 
Mishna Berura served a role as a law book trying to preserve the strength of faith in an often volatile world, a daunting task. Yet, as time has shown, the Mishna Berura does manage to live up to the task. Indeed, much of the work deals with the inherent conflicts of a Jewish person's attempt to maintain his traditions and integrity in a chaotic and unyielding society. The consummate juggler, the Hafetz Hayyim (as Rabbi Kagan is known, in a reference to another of his works) often addresses the reality of complex situations and steadfastly refuses to limit his halakhic tools only to a few principles; he balances numerous central propositions while resolving uncertainty, all at the same time. For him, the best outcome is the one that is most consistent with the totality of the picture-which is what makes the methodology of the Mishna Berura so hard to grasp and the work so incredibly sophisticated. ${ }^{6}$ Rabbi Kagan also manages to do all this while keeping the work extremely simple and easy to use, so that the reader who simply wants to know the answer to a question can find it without difficulty.

Today, the Mishna Berura has gained widespread recognition and is considered authoritative by essentially all of contemporary Orthodox Jewry, a measure of greatness that few works of Halakha have attained. For scholar and layman alike, it exerts widespread normative influence on the daily life of an observant Jew. Of course, it is not the case that every single one of the Mishna Berura's decisions are universally followed, since rulings in Orah Hayyim, which cover the ritual aspects of daily life, have continued to maintain diversity as a result of local customary practice or Hassidic affiliations. Nonetheless, the Mishna Berura is nevertheless a primary source for those who are looking for what constitutes normative practice within Orthodox Judaism as a whole. As Aharon Feldman, editor of the English translation of the Mishna Berura, writes in its introduction:

6 The Gra, too, was creative in his approach to defining Jewish law, though his thoughts, inspiration, and analysis tend to center around one central question: right or wrong? 
The Mishnah Berurah has undergone countless printings. It is studied and restudied by all rabbis, students, and scholars; it can be found-and is consulted-in the home of every learned Jew. The statement, "The Mishnah Berurah says..." is enough to settle nearly any halachic question. ${ }^{7}$

Similarly, Israeli Supreme Court Justice Eliyakim Rubenstein calls the Mishna Berura "the standard commentary on the Shulhan Arukh for all of Torah Jewry." Given the Mishna Berura's widespread acceptance as a halakhic authority, it is remarkable how little his halakhic methodology has been critically examined. However, Benjamin Brown, the great scholar of Jewish law and practice, has given an alternative account of the Mishna Berura's methodology. Because the Mishna Berura is such a widespread authority in matters of Jewish law, and because there is such a lacuna in the systematic study of its methodology, we have undergone an examination of the methodology of this incredibly successful work.

7 Israel Meir, Aharon Feldman, and Aviel Orenstein, Mishnah Berurah: The Classic Commentary to Shulchan Aruch Orach Chayim, Comprising the Laws of Daily Jewish Conduct (Spring Valley: Feldheim, 1989), xii.

8 Eliyakim Rubenstein, "Halakha and Mussar for Everyone: On the Life and Works of the Hafetz Hayyim,” in Berakhah le-Avraham Asufat Ma'amarim li-Khevod ha-Rav Prof. Avraham ha-Levi Shțainberg mi-Peri 'Itam shel Yediday u-Mokiray bi-Melot lo Shishim Shanah; be-Tosefet Ketavim shel Avot ha-Mishpahah, ed. Yitshak Ilan Shtainberg and Avraham Steinberg (Yerushalayim: Y. Shțainberg, 2008), 462. 